\title{
Emoción, Sentimiento y Pasión en Kant ${ }^{1}$
}

\author{
Ana Marta González²
}

RESUMEN: En este trabajo se analiza el modo en que Kant distingue entre sentimiento y emoción, por un lado, y emoción y pasión, por otro, para mostrar: 1) que bajo el término "emoción" (Affekt) Kant entiende principalmente la afección orgánica privada de contenido cognitivo, aunque precedida y seguida de representaciones; 2) que la emoción constituye un elemento integral de lo que Kant denomina "sentimiento" (Gefühl), término del que se sirve para designar la dimensión subjetiva de la experiencia en sentido amplio, no limitado a la afección empírica; 3) que su concepción negativa de la pasión justifica la posterior distinción entre emoción y pasión introducida en los estudios científicos.

PALABRAS CLAVE: encanto, juicio estético, salud, arte y juego, deseo.

\section{INTRODUCCIÓN}

En el estudio de la emoción Kant no suele ser un autor de referencia, en parte porque lo que tiene que decir sobre las emociones no es, en general, muy positivo. Sin embargo, un análisis pormenorizado del modo en que Kant se refiere a la emoción, y cómo la distingue de otros términos relacionados, tales como "sentimiento", "sensación", o "pasión", permite mostrar la relevancia de las distinciones que establece para desbrozar conceptualmente un terreno especialmente complejo, y apreciar cómo su pensamiento anticipa el sentido que adquirirá el término "emoción" en el discurso científico posterior, pues Kant ya considera la "emoción” como el aspecto orgánico del sentimiento que, si bien tiene su origen en representaciones objetivas, se refiere fundamentalmente a la cualidad placentera o dolorosa de la afección que experimenta el sujeto.

Al mismo tiempo, en su análisis del sentimiento estético, Kant abre también las puertas a una visión más rica de experiencia, que va más allá de la

\footnotetext{
${ }^{1}$ Este trabajo forma parte del proyecto "Acción, emoción e identidad" (FFI2012-38737-C03-01), financiado por el Ministerio de Economía y Competitividad del Gobierno de España. http://dx.doi.org/10.1590/S0101-31732015000300006

${ }^{2}$ Profesora de Filosofía Moral. Departamento de Filosofía e Investigadora del Instituto Cultura y Sociedad. Universidad de Navarra, España. Correo electrónico: agonzalez@unav.es
} 
simple afección empírica, pues no excluye cierta pretensión de universalidad, presentando además la virtualidad de estimular una intensa actividad psíquica - representaciones imaginativas, contenidos cognitivos - que expresa y acentúa o refuerza la misma experiencia emocional. Según esto, la emoción no solo iría precedida, sino también seguida de representaciones. Es decir, si bien la emoción en sentido estricto sería algo del sentimiento - concretamente, su dimensión orgánica -, el sentimiento como tal sería algo más amplio, algo del espíritu, como luego enfatizarán los románticos: Gefühl ist alles, dirá el Fausto de Goethe.

Por otro lado, Kant introduce una significativa diferencia entre emoción y pasión, según la cual el concepto de pasión, como acto de la facultad de desear, sí incorporaría contenido intencional, aunque con connotaciones moralmente negativas. Precisamente este punto permitiría incluir la aproximación kantiana a la pasión entre los precedentes del cambio del que habla Dixon (2003), para quien una de las motivaciones principales para el abandono del término pasión y la correlativa adopción del término "emoción” por parte de la biología o la psicología habría sido el intento de encontrar un lenguaje psicológico "secular", no cargado de las connotaciones morales asociadas al término "pasión". Cuando vean la luz los trabajos de Darwin o de James sobre las "emociones", el término "pasión" ha desaparecido ya del lenguaje de la psicología, remplazado por el más aséptico término "emoción”, y arropado por una terminología supuestamente más acorde con las aspiraciones científicas de la psicología (SOLOMON 1983, p. 142-143).

\section{SeNTIMIENTO Y EMOCión EN LA CRÍTICA DEL JUICIO}

Tanto en la Critica del Juicio como en la Antropología, Kant distingue claramente entre sensación (Empfindung) y sentimiento (Gefühl), por un lado, y entre pasión (Leidenschaft) y emoción (Affekt), por otro ${ }^{3}$. Sin embargo, precisar la relación entre sentimiento (Gefühl) y emoción (Affekt) es más difícil. Es lo que trataremos de hacer en este epígrafe ${ }^{4}$.

\footnotetext{
${ }^{3}$ En general habla de "Affekt", y alguna vez de "Rührung" (KANT, KU: 223, 226, 273).

${ }^{4}$ Las obras de Kant se citarán en el texto empleando las iniciales de la edición alemana, seguidas del número de volumen y de página en la edición de la Academia. Al citar la Antropología se añadirá la página de la edición en castellano: Crítica del Juicio: KU, 5: p; Metafísica de las Costumbres: MS, 6: p; Ideas para una historia universal: Id, 7: p; Antropología en sentido pragmático: Anth, 7: p.; Religión dentro de los límites de la mera razón: Rel, 6: p.
} 


\subsection{LA CUALIDAD SUBJETIVA DE LOS SENTIMIENTOS}

Bajo el término "sentimiento" Kant entiende el aspecto subjetivo de la sensación, inseparablemente vinculado al placer o dolor, y, según expone, privado de contenido cognitivo, incluso "[...] aquel por el cual el sujeto se conoce a sí mismo" (KU, 5:206). En efecto: según Kant, en la sensación hemos de distinguir cuidadosamente el aspecto cognitivo, referido al objeto, y la afección, que se refiere exclusivamente al sujeto. Y propone aludir a esta última con la palabra "sentimiento":

Vamos a dar el nombre, por lo demás usual, de sentimiento, a lo que tiene siempre que permanecer subjetivo y no puede de ninguna manera constituir una representación de un objeto. El color verde de los prados pertenece a la sensación objetiva, como percepción de un objeto del sentido; el carácter agradable del mismo, empero, pertenece a la sensación subjetiva, mediante la cual ningún objeto puede ser representado, es decir, al sentimiento, mediante el cual el objeto es considerado como objeto de la satisfacción (que no es conocimiento del objeto) (KU, 5: 206).

Kant, por tanto, restringe el término sentimiento a la "[...] determinación del sentimiento del placer o de dolor" en el sujeto, prescindiendo de la referencia a la representación que pudo haberlo suscitado. Eso no significa que toda representación esté necesariamente ausente; de hecho, como ha sido puesto de manifiesto (BORGES, 2004), en su caracterización del sentimiento de simpatía como "[...] placer o desagrado por el estado de satisfacción o de dolor ajenos” (MS, 6: 456), ya va implícita cierta representación; con mayor motivo si debe ser posible comunicarse entre sí los sentimientos, en lo que, según Kant, consiste el deber de humanidad (MS, 6: 456). Ambas cosas, sin embargo, han de conciliarse con la insistencia de Kant en que el término "sentimiento" connota exclusivamente la dimensión subjetiva de la sensación, que puede ser placentera o dolorosa, aunque sin excluir cierta diversidad cualitativa. Dicha conciliación es posible en la medida en que su análisis del sentimiento revela un sentido más rico de experiencia.

Después de todo, los sentimientos pueden ser muy variados. Algunos de ellos se relacionan directamente con la facultad de desear, porque satisfacen o contrarían nuestros apetitos (sentimientos patológicos, que tienen su origen en estímulos sensibles y que pueden o no facilitar la receptividad del ánimo a deberes morales ${ }^{5}$ ), o nuestra voluntad (sentimiento propiamente moral, que

\footnotetext{
${ }^{5}$ No solo la simpatía (MS, 6:457), sino también el sentimiento de auto-estima (Id, 8: 20).
} 
tiene su origen en la representación de la ley). Pero Kant sostiene que, además, hay sentimientos estéticos, que placen desinteresadamente, sin relación inmediata a los deseos sensibles o a la voluntad (KU,5:187), sino de un modo puramente contemplativo (aunque sin fundarse en concepto alguno, y sin tener concepto alguno como fin (KU, 5:209)).

De hecho, Kant considera que la mezcla de un interés extraño estropea el juicio de gusto, lo que ocurre principalmente en los juicios estéticos sobre algo que (además) produce placer o dolor (KU, 5:223). Por eso insiste en que el juicio de gusto puro es aquel en el que "[...] el encanto y la emoción no ejercen influjo alguno (aunque se dejen éstos enlazar con la satisfacción en lo bello)" (KU, 5:223).

Más adelante, Kant explicará el alcance de esta tesis:

Si la satisfacción en el objeto se funda únicamente en el hecho de que éste deleita mediante encanto o emoción, entonces no se puede exigir a ninguna otra persona que esté de acuerdo con el juicio estético que enunciamos, pues sobre eso cada uno interroga, con razón, solo su sentido privado.... (KU, 5: 278).

Implícita en esta consideración es que encanto y emoción son dependientes de la particular constitución empírica del sujeto, mientras que la satisfacción en el objeto, propia del sentimiento estético pretende cierta universalidad; pensar que la belleza depende de dicho encanto o emoción impediría dar cuenta de la pretensión de universalidad con la que se nos presentan los juicios estéticos. El sentimiento de belleza, el placer peculiar que acompaña a los juicios estéticos, no se confunde con el placer peculiar que proporciona la emoción. Esto sugiere una importante diferencia conceptual entre sentimiento y emoción. Ambos términos connotan placer o dolor; sin embargo, el placer puramente estético, asociado al libre juego de facultades, se debe a la misma forma del objeto, y es, en ese sentido, indirectamente informativo del objeto; mientras que el placer derivado de la emoción es un placer derivado del ajuste del objeto a nuestra constitución orgánica, que en último término remite al apetito. Aun sin llegar a constituir conocimiento en sentido estricto, es decir, sin llegar a constituir auténtica representación de un objeto, el sentimiento estético no puede reducirse a una afección del sujeto, pues se vincula a una cierta estructura del objeto. Al mismo tiempo, en lo que tiene de afección, se debe a la peculiar constitución empírica del sujeto, y es, en ese sentido, una emoción. 


\subsection{EMOCIÓN COMO AFECCIÓN EMPÍRICA}

El contexto en el que se sitúan estas afirmaciones muestra que el término "emoción" (Affekt) tiene en Kant un sentido muy preciso: una afección placentera o dolorosa - y por eso mismo un sentimiento, según la definición general apuntada más arriba -, que, al igual que el "encanto", puede contaminar el juicio de gusto, presuntamente porque el agrado que le es peculiar interfiere en la formación de un sentimiento estético puramente contemplativo.

La emoción, sea cual sea su origen, constituye la respuesta orgánica a un estímulo placentero o doloroso para la sensibilidad, que a su vez satisface o contraría a la razón. Kant explica el agrado peculiar que acompańa a esta respuesta orgánica como una 'momentánea suspensión y desbordamiento posterior más fuerte de la fuerza vital', y excluye expresamente su vinculación a la belleza:

La emoción, sensación en donde el agrado se produce solo mediante una momentánea suspensión y un desbordamiento posterior más fuerte de la fuerza vital, no pertenece en modo alguno a la belleza... un puro juicio de gusto no tiene, como fundamento de determinación, ni encanto ni emoción: en una palabra, ninguna sensación, como materia del juicio estético. (KU, 5: 226).

El agrado característico de la emoción, entonces, sería el efecto psíquico en el sujeto de las fluctuaciones de la "fuerza vital" de su organismo. Con ello Kant subraya el fundamento biológico de la emoción. Ciertamente, el hecho de que incida principalmente en la dimensión biológica de este fenómeno psíquico no debe llevarnos a excluir toda referencia a representaciones en su caracterización de la emoción: no solo porque las mismas fluctuaciones de la fuerza vital, propias de la emoción, se deben a alguna representación, sino porque no es posible diferenciar una emoción de otra sin cualificar de alguna manera las representaciones que están en su base. Esto se advierte, por ejemplo, en la caracterización de emociones particulares, que, de manera incidental, lleva a cabo el propio Kant también en la Crítica del Juicio, cuando describe la "estupefacción" como "emoción en la representación de la novedad, que supera lo que se esperaba", de la cual ha de distinguirse la "admiración" - que queda descrita, a su vez, como "[...] una estupefacción que no cesa al perderse la novedad" (KU, 5: 272). Este tipo de distinciones presta cierta plausibilidad a la tesis que trata de reconocer en Kant ciertos atisbos de un concepto intencional de emoción. 
Ahora bien, el hecho de que las emociones puedan distinguirse en atención a la diversidad de las representaciones que están en su base, no parece suficiente para sostener que Kant mantiene "un concepto intencional de emoción”. Más exacto sería decir que enmarca la emoción en una experiencia más amplia, de la que no está ausente la intencionalidad; que, dentro de una consideración general del sentimiento como afección subjetiva, introduce una diferenciación entre la pretensión informativa sobre el objeto, característica de los sentimientos estéticos, y la afección orgánica que de ordinario acompaña a dicha pretensión.

La emoción, en efecto, aparece como un elemento integrante del sentimiento, precedido de representaciones, y eventualmente seguido de apetitos y más representaciones, las cuales, sin embargo, permanecen exteriores al movimiento orgánico en el que se hace consistir la emoción en sentido estricto. Según esto, mientras que el sentimiento designa la afección subjetiva en general, la emoción debe concebirse como la dimensión orgánica de dicha afección, una dimensión que, además de ser antecedente o consiguiente a los actos de la facultad de desear, resulta concomitante a los juicios estéticos.

\subsection{SENTIMIENTO ESTÉTICO Y EMOCIÓN}

Así pues, la emoción no es para Kant el factor determinante del sentimiento de belleza. Pero esto no significa que el sentimiento de belleza no pueda enlazarse con algún encanto o con alguna emoción. Con otras palabras: una cosa es que la emoción, como respuesta orgánica de la facultad de desear, no sea determinante del juicio de gusto, y otra que el juicio de gusto no suscite un sentimiento peculiar, capaz de estimular una intensa actividad psíquica.

De hecho, el propio Kant afirma que el sentimiento de belleza “[...] lleva consigo directamente un sentimiento de impulsión a la vida, y, por tanto, puede unirse con el encanto y con una imaginación que juega”. Por su parte, el sentimiento de lo sublime no consiste tanto en un sentimiento de impulsión a la vida como en "[...] una suspensión momentánea de las facultades vitales seguida inmediatamente por un desbordamiento tanto más fuerte de las mismas; y así, como emoción, parece ser, no un juego, sino seriedad en la ocupación de la imaginación" (KU, 5: 244-5). Esto se debe a que, a diferencia de la experiencia de lo bello - que se refiere a la forma del objeto- lo sublime puede encontrarse en un objeto sin forma (KU, 5: 244-5), que invita a pensar una totalidad a partir de una ilimitación, y que, por eso mismo, se presenta 
como la exposición de un concepto de la razón, que sucesivamente atrae y rechaza al espíritu. En todo caso, esto hace que dicho placer "[...] no pueda unirse con encanto"; y que deba más bien llamarse "placer negativo", pues consiste más bien en "admiración o respeto" (KU, 5: 244-245).

A juzgar por estas palabras, Kant reserva el término "encanto" a la clase de sentimientos placenteros que se asocian al sentimiento de belleza, en la medida en que éste suscita una imaginación que juega; mientras que vincula la emoción a los sentimientos que ocupan la atención en la experiencia de lo sublime. Pero tanto el sentimiento de lo bello como el de lo sublime suscitan una intensa actividad psíquica, y cada uno a su modo dispone el espíritu para el sentimiento moral:

El juicio estético sobre ciertos objetos que lo ocasionan, es un principio constitutivo en relación al sentimiento de placer o dolor. La espontaneidad en el juego de las facultades del conocimiento, cuya concordancia encierra el fundamento de ese placer, hace el concepto pensado aplicable en sus consecuencias para instituir el enlace de la esfera del concepto de la naturaleza con la del concepto de la libertad, en cuanto favorece al mismo tiempo la receptividad del alma para el sentimiento moral. (KU, 5: 197).

El sentimiento de lo bello dispone al sentimiento moral por el desinterés que lo acompaña (5:267); el sentimiento de lo sublime, porque despierta un cierto sentido de nuestra determinación racional (KU, 5: 257-8). Desde este punto de vista, puede decirse que ambos sentimientos nos abren las ventanas de la subjetividad (KU, 5: 192). Ésta puede considerarse una aportación significativa a la teoría del sentimiento, que en su versión tradicional no había explorado esta vía.

Sin embargo, a diferencia del sentimiento, la emoción por sí misma, como mera afección orgánica, producida por la contracción y distensión de la fuerza vital, no abre ninguna ventana. Kant afirma taxativamente que la emoción es ciega (KU, 5: 272), y por eso, en términos absolutos no accede a considerar sublime (KU, 5: 272) ni siquiera una emoción como el entusiasmo que, desde el punto de vista estético, sí admitiría este adjetivo (KU, 5: 272).

La sublimidad estética del entusiasmo se debe a que moviliza de manera duradera energías psíquicas directamente por ideas de la razón, y no simplemente por representaciones sensibles. Sin embargo, lo sublime como tal no se deja encerrar en los confines de la emoción. Por el contrario, Kant hace 
notar que "[...] la falta misma de emoción (apatheia, phlegma, in significatu bono) de un espíritu que sigue enérgicamente sus principios inmutables es sublime, y, en modo mucho más excelente, porque tiene de su parte al mismo tiempo la satisfacción de la razón pura”. (KU, 5:272).

La no-sublimidad de las emociones tiene que ver indudablemente con su dependencia de la constitución empírica, orgánica, del sujeto. De hecho, Kant lamenta la confusión conceptual consistente en llamar sublimes a los movimientos tempestuosos del espíritu que únicamente sirven a la salud, pero no dan vigor moral al ánimo (KU, 5: 273).

\subsection{EMOCIONES Y SALUD. EMOCIONES ENÉRGICAS Y DEPRIMENTES}

Efectivamente, según Kant, los efectos de la emoción en la salud son comparables a los que producen los masajes, "[...] solo que allí el principio motor está, en gran parte, dentro de nosotros, y aquí, en cambio, totalmente fuera" (KU, 5: 274). Los eventuales efectos saludables de los movimientos suscitados por la emoción son también lo que tiene en mente en la Crítica del Juicio, cuando aventura una posible explicación de los sueńos, como algo previsto por la naturaleza para activar la imaginación y, por su medio, mover internamente las facultades vegetativas - facilitando también la digestión cuando se ha comido mucho (KU, 5: 379).

En sus pronunciamientos sobre la emoción, Kant suele subrayar la dimensión biológica de este fenómeno psíquico. Por esta razón, tiende a considerarla como un elemento del sentimiento, sin llegar a identificarla completamente con él: mientras que el sentimiento designa la afección subjetiva en su totalidad, agradable o dolorosa, pero no siempre emotiva (como en el sentimiento de belleza, que place sin mover), la emoción designaría, principalmente, el aspecto orgánico de algunos sentimientos, el cual es, por un lado, efecto de una serie de representaciones imaginativas -que sin embargo no siempre conllevan emoción - y, por otro, causa de movimientos del organismo y de ulterior actividad psíquica.

Que el efecto sobre el organismo constituye la principal determinación de la emoción para Kant se muestra en el criterio que emplea en la Crítica del Juicio para clasificar las emociones, donde habla de dos tipos o especies de emociones: la especie "enérgica" - "[...] que excita la consciencia de nuestras fuerzas para vencer toda resistencia" - y la especie "deprimente" - que "[...] 
nace del esfuerzo mismo para resistir un objeto de dolor" -, de las cuales solo las primeras merecerían el calificativo de (estéticamente) sublimes, mientras que las segundas podrían tal vez ser consideradas bellas desde el punto de vista sensible, pero en modo alguno nobles (KU, 273).

En conformidad con su concepto marcadamente biológico de emoción, esta clasificación no alude en primer término a diferencias cualitativas, sino a consideraciones de "fuerza vital". En efecto, como acabamos de ver, la diferencia se establece entre aquellas que van acompañadas por la conciencia de las propias fuerzas para vencer, o aquellas otras que van acompañadas del esfuerzo para resistir el dolor -. Y tal diferencia de emociones cualifica también a los sentimientos:

De aquí que los sentimientos, que pueden crecer en fuerza hasta la emoción, sean también muy diferentes. Se tienen sentimientos valerosos y se tienen tiernos. Estos últimos, cuando crecen hasta la emoción, no sirven para nada; la inclinación a ellos se llama sensiblería. (KU, 5: 273).

En este pasaje los sentimientos aparecen como afecciones dinámicas, "[...] que pueden crecer en fuerza hasta la emoción"; la emoción se presenta aquí, entonces, como un punto álgido del sentimiento; un momento en el que éste encuentra su máxima expresión orgánica, tanto si se trata de sentimientos sublimes -que ejemplifican emociones de tipo enérgico- como sentimientos bellos -que ejemplifican emociones de tipo deprimente-.

La valoración que le merecen estos últimos, así como sus emociones, es sin embargo muy distinta de los primeros. Como es sabido, Kant no se muestra especialmente indulgente con la tendencia a la sensiblería, que se alimenta de las emociones de la especie deprimente, y así, llegado a este punto se explaya con detalle, censurando desde las novelas y dramas llorones, hasta las manifestaciones ridículas de una religiosidad sentimental (KU, 5: 273).

\subsection{EMOCIÓN, ARTE Y JUEGO}

$\mathrm{Al}$ igual que la contemplación de la naturaleza o del arte puede suscitar un sentimiento estético, al que se pueden unir naturalmente el encanto y la emoción, así también la emoción tiene un lugar en las bellas artes: no como 
elemento determinante de su belleza ${ }^{6}$, sino como algo que se deja unir a ella naturalmente, provocando el encanto y el movimiento del espíritu. Esto es especialmente claro en la música, que Kant califica como la "[...] lengua de las emociones" (KU, 5:328).

Ahora bien, del mismo modo que distinguimos lo bello y lo agradable, así también debemos distinguir las artes bellas, que placen por la forma, y las artes agradables. Estas últimas toman en cuenta la forma, pero se ordenan principalmente al deleite y la diversión, y por eso se relacionan con las emociones suscitadas por el juego. Kant distingue tres tipos de juego: de azar, de sonido, y de pensamiento, que se buscan sin otro fin que el deleite que proporcionan - como lo muestra, sugiere Kant, el hecho de que la vida social nocturna gire en torno a ellos (KU, 5:331).

Lo característico del deleite que se persigue mediante el juego reside en el cambio: como ya apuntara Aristóteles (EN, X, 4, 1175 a 6-10) cambiar produce placer, ya se trate de un cambio de sensaciones o de representaciones. Ciertamente, en los juegos de azar se presupone además un interés - satisfacer la vanidad, o la utilidad -, pero, tal y como subraya Kant, lo que atrae del juego de azar no es el interés por sí solo, sino el modo de procurárselo, lo cual prueba que no hay juego - ni siquiera juego de azar- sin forma. Esto es todavía más claro en el caso de los juegos que solo requieren el cambio de sensaciones - "[...] cada una de las cuales tiene su relación con la emoción, sin tener el grado de una emoción, y excita ideas estéticas" - o el cambio de representaciones en el juicio - "[...] mediante las cuales no se produce pensamiento alguno que lleve consigo algún interés, pero el espíritu es, sin embargo, vivificado" (KU, 5:331).

Ahora bien, lo característico de las artes agradables, a diferencia de las artes bellas, es que el encanto y la emoción asociado con el modo del cambio no solo "se dejan relacionar" con el sentimiento específicamente estético, sino que constituyen un elemento integrante de ellas. Eso explica que a veces juguemos como si nos fuera en ello la vida:

\footnotetext{
6 "En todo arte bello lo esencial está en la forma, que es conforme a fin para la contemplación y para el juicio, en donde el placer es al mismo tiempo cultura, y que dispone el espíritu para ideas, proporcionándole, por tanto, receptividad para varios placeres y entretenimientos, y no en la materia de la sensación (en el encanto o en la emoción), en donde se trata solo de goce, que no deja nada en la idea y embota el espíritu, produciendo poco a poco asco del objeto y tornando el alma, por la conciencia de su disposición contraria al fin en el juicio de la razón, descontenta consigo misma y caprichosa”. KU, 5: 326.
} 
Las emociones de esperanza, temor, alegría, cólera, desdén juegan allí también, cambiando a cada momento su papel, y son tan vivas que por ellas, como por un movimiento interior, todo el negocio de la vida parece ser favorecido en el cuerpo, como lo demuestra la vivacidad del espíritu, producida por ello, aunque ni se ha ganado ni se ha aprendido nada. (KU, 5: 321-2).

En efecto: una peculiaridad del juego, en la que Kant se detiene no sin cierto asombro, es que en él empleamos muchas fuerzas psíquicas, sin que realmente obtengamos más ganancia que la activación del organismo, de tal manera que, en el juego, la misma actividad del espíritu se pone al servicio de la salud. Esto se ve en el caso de la música y las bromas,

[...] dos clases de juego con ideas estéticas, o también con representaciones del entendimiento, mediante las cuales, al fin, nada es pensado, y que solo pueden deleitar por su cambio, aunque vivamente: por lo cual dan a conocer bastante claramente que la animación en ambas es meramente corporal, aunque excitada por ideas del espíritu, y que el sentimiento de la salud, mediante un movimiento de las entrańas correspondientes a aquel juego, constituye todo el deleite que una sociedad alegre aprecia como tan fino y espiritual. (KU, 5: 331-2).

Así pues, aunque las artes agradables exciten o jueguen con ideas estéticas no valen como bellas artes, porque no se determinan únicamente por la forma, sino que persiguen directamente el encanto o la emoción, y, por esta razón, sirven más al provecho del cuerpo que del espíritu, "[...] pudiéndose con el alma también llegar hasta el cuerpo, y usar aquella como médico de éste" (KU, 5:332). Centrándose en este aspecto saludable de las emociones suscitadas por las artes agradables, Kant detalla incluso lo que bien puede considerarse los fundamentos de terapias basadas en la música o la risa:

En la música, ese juego va de la sensación del cuerpo a las ideas estéticas (de los objetos para emociones), y de éstas vuelve después de nuevo hacia atrás, al cuerpo, pero unido con más fuerza. En la broma (que, como la música, merece contarse más bien entre las artes agradables que entre las bellas) comienza el juego por los pensamientos, que todos juntos, en cuanto quieren expresarse sensiblemente, ocupan también el cuerpo, y al relajarse, de pronto, el entendimiento en esa exposición, en donde no encuentra lo esperado, siéntese el efecto de ese relajamiento en el cuerpo, mediante una vibración de los órganos, que favorece el restablecimiento de su equilibrio y tiene en la salud un efecto bienhechor..... (KU, 5: 332). 
La distinción entre sentimiento y emoción que nos sale al paso en nuestro recorrido por la Crítica del Juicio podría sugerir una equivalencia con la dualidad afecto-sensualidad que caracterizaba el concepto medieval de pasión, en la cual el afecto incluía un elemento cognitivo, susceptible de dirección racional, mientras que la sensualidad designaba el aspecto orgánico de la pasión, que se sustrae a tal dirección (AQUINO, De, Ver., q. 25, a.4, co.; S.th. I, q. 81, a.3; S.th. I.II, q. 17, a. 7). Sin embargo, Kant desvincula el sentimiento (y la emoción) de la pasión con una radicalidad que no tiene precedente.

En efecto, en Kant, el concepto de "emoción" se desvincula de toda referencia a la acción para designar exclusivamente un elemento del sentimiento. Por esa razón considera que el lugar apropiado para estudiarlas habría sido la segunda parte de la Antropología, y no la tercera - dedicada a la facultad de desear -; si, en cambio, lo trata en el libro tercero es precisamente para aclarar la confusión que suele seguirse del parentesco existente entre ambos fenómenos. (Antr., 7: 235, (162)).

\section{EL CONCEPTO KANTIANO DE PASIÓN}

Kant no niega toda relación entre las emociones y la facultad de desear; después de todo, las emociones, en cuanto afecciones acompañadas de placer o dolor, reflejan la reacción orgánica de un sujeto ante un determinado objeto y disponen eventualmente a la formación de un deseo. Sin embargo, el deseo como tal, caracterizado como "[...] autodeterminación de la fuerza de un sujeto por medio de la representación de algo futuro como un efecto de la determinación" (Antr. 7: 251 (184)) tiene más que ver con la imaginación de un efecto posible - algo que satisfaga al sujeto, en el sentido de gratificarle (deseo sensible) o convenirle (deseo racional) - que con el sentimiento propiamente dicho (Antr. 7: 154 (51-52)), al cual parece reducirse ahora la emoción, como uno de sus elementos, del que está ausente todo contenido cognitivo.

Como hemos visto, el concepto de "emoción" tiende a identificarse con la afección orgánica suscitada por una determinada percepción - se trate de una sensación o de una imaginación, o, en el caso del sentimiento moral, una representación racional -, dejando en penumbra el objeto que la ha motivado ${ }^{7}$. Por el contrario, el modo en que Kant precisa el concepto de

\footnotetext{
${ }^{7}$ Estoy de acuerdo con M. Borges, en que el concepto de emoción de Kant no excluye contenidos intencionales y que, por tanto, no se puede asimilar sin más a la teoría "placer-dolor"; sin embargo, como he explicado antes, Kant tiende a favorecer una visión no-cognitiva y causalista de las
} 
pasión (Leidenschaft), como un acto de la facultad de desear, permite afirmar que, para él, el concepto de pasión retiene un sentido "cognitivo", aunque radicalmente negativo, por radicalmente opuesto a la razón.

\subsection{Propensión, inClinación y pasión}

En la Antropología, Kant distingue entre "propensión”, “inclinación” y "pasión”, en los siguientes términos:

La posibilidad subjetiva de que surja un cierto apetito, anteriormente a la representación de su objeto, es la propensión - la interna compulsión de la facultad apetitiva a tomar posesión de este objeto, antes de que se le conozca, el instinto (como el impulso sexual o el impulso paternal de los animales a proteger a sus crías, etc).- El apetito sensible que le sirve al sujeto de regla (hábito) dícese inclinación.- La inclinación que impide a la razón compararla, en vista de una cierta elección, con la suma de todas las inclinaciones, es la pasión (passio animi). (Antr., 7: 265 (203)).

Según esto, la pasión es una clase especial de inclinación, a saber: la inclinación que, a la hora de elegir, impide a la razón comparar el objeto de la misma pasión con la suma de todas las inclinaciones - que en otro lugar Kant llama felicidad -. Ahí ya se ve que la pasión, en la mente de Kant, desempeña el papel de obstáculo a la libertad.

A su vez, conviene advertir la diferencia implícita entre inclinación regla del apetito sensible - e instinto: el instinto es una compulsión interna del apetito a apoderarse de su objeto antes de que tal objeto sea conocido, o representado. Así, el instinto es la actualización inmediata de la propensión, a la cual se debe la posibilidad de apetecer algo, incluso antes de que el algo en cuestión adquiera una forma definida (Rel, 6: 29 (46)).

Pues bien: Kant no dice que las pasiones sean casos de instinto, sino inclinaciones: es decir, reglas por las cuales el apetito se dirige a un objeto, el cual, a diferencia del instinto, sí es conocido, siquiera de manera habitual. En

emociones. Por otro lado, me parece que, incluso aunque mediante una lectura más completa de los textos reconozcamos el contenido intencional de los sentimientos, lo principal de la emoción, para Kant, sigue estribando en la afección orgánica del sujeto. Incluso aunque reconozcamos en las emociones un contenido cognitivo informativo para el sujeto - es el caso de la simpatía, que nos hace receptivos a las necesidades ajenas -, tal contenido no tiene de por sí un valor propiamente moral (exceptuado, claro está, el sentimiento moral). 
este sentido, lo que distingue a las inclinaciones de los instintos es que aquéllas constituyen una actualización de las propensiones en conformidad con ciertas representaciones sensibles; en otro lugar Kant define tales inclinaciones como "[...] apetito sensible habitual" (Antr. 7: 252 (184)) - al que todavía en otra ocasión denomina concupiscencia ${ }^{8}$. Entre las inclinaciones, pues, se cuentan las pasiones, cuya nota definitoria, como hemos dicho, es su oposición a la razón: "La inclinación difícil o absolutamente invencible por la razón del sujeto es la pasión". (Antr., 7: 251, (184)).

Según Kant, las pasiones son inclinaciones que se oponen a la razón, de un modo bien preciso: impiden la actividad comparativa de la razón. En términos clásicos diríamos que "atan" o "ligan" la razón. Kant explica esta "ligadura" como una forma particular de impedimento, una inclinación muy fuerte por la cual la razón ya no puede comparar el objeto de la pasión con la suma de todas las inclinaciones -tarea que Tomás de Aquino atribuía a una facultad exclusivamente humana, la "cogitativa", encargada de relacionar la razón particular de bien, presente en la pasión, con el bien en general (GONZÁLEZ, 2011).

En cuanto que bloquea la actividad comparativa de la razón, de la que depende la elección, la pasión se presenta como algo contrario a nuestra condición racional. De ahí la valoración radicalmente negativa que el término "pasión” recibe en Kant, y que le lleva a distinguirlas netamente de lo que él llama "emociones".

\subsection{PASIONES Y EMOCIONES: DOS “ENFERMEDADES” DISTINTAS}

Es en el tercer libro de la Antropología, donde Kant acomete la tarea de distinguir emoción y pasión, consciente de que a menudo se confunden. Para Kant, sin embargo, existe entre ellas una diferencia específica:

\footnotetext{
8 "Por propensión (propensio) entiendo el fundamento subjetivo de la posibilidad de una inclinación (apetito habitual, concupiscencia) en tanto ésta es contingente para la humanidad en general". Rel. 6: 29 (p. 46). Cf, también Metafísica de las Costumbres: MS, 6: 213. B. Herman ha tratado de aclarar la noción kantiana de concupiscencia, examinando por qué Kant considera, correctamente, en mi opinión, que actuar según una máxima de beneficencia entra en conflicto con la concupiscencia y no con la felicidad. A partir de ahí Herman observa que lo que se opone a la concupiscencia es, precisamente, el actuar por deber, implícito en el cumplimiento moral del deber de beneficencia, lo cual excluye el actuar según cierta clase de deseos, precisamente aquellos que son estimulados por la concupiscencia (HERMAN 2007, p. 231-2).
} 
Las emociones se distinguen específicamente de las pasiones. Aquéllas se refieren solo al sentimiento; éstas pertenecen a la facultad de desear, y son inclinaciones que dificultan o imposibilitan toda determinabilidad de la voluntad mediante principios; aquellas son tormentosas y sin premeditación; éstas perseverantes y reflexivas [...]. (KU, 5:272; Antr. 7: 272 (218)).

En efecto: mientras que la emoción solo bloquea momentáneamente la actividad reflexiva, la pasión es una inclinación invencible, que subordina la actividad reflexiva a sus propios fines irracionales:

La inclinación difícil o absolutamente invencible por la razón del sujeto es una pasión. Por el contrario, es el sentimiento de un placer o displacer en el estado presente, que no permite se abra paso en el sujeto la reflexión (la representación racional de si debe entregarse o resistirse a él), la emoción. (Antr, 7: 252 (184-5)).

Así pues, aunque, según Kant, las dos afectan a la actividad racional, la pasión lo hace de una manera específicamente distinta a la emoción, porque contamina desde su raiz el obrar racional. Para ilustrarlo muestra la diferencia entre la emoción de la cólera y la pasión del odio identificando un elemento común que, sin embargo, se desarrolla de manera distinta en cada caso:

Así, la indignación, como cólera, es una emoción: pero como odio (deseo de venganza) es una pasión. Esta última no puede nunca y en ninguna relación ser llamada sublime, porque en la emoción, la libertad del espíritu queda, desde luego, suspendida, pero en la pasión es anulada. (KU, 5: 272, nota; Antr. 7: 272 (218)).

Si nos preguntamos por qué un mismo estímulo puede dar lugar a respuestas distintas entramos ya en el terreno moral. Pues aunque hay temperamentos más emotivos y otros más proclives a la pasión, en la medida en que esta última recibe una valoración tan negativa, no puede consistir simplemente en un condicionamiento natural. De hecho, el propio Kant apunta que las pasiones "se incuban". Así ocurre, por ejemplo, con el entusiasmo:

En el entusiasmo, como emoción, la imaginación no tiene freno; en la exaltación, como pasión incubada y arraigada, no tiene regla. El primero es un accidente que pasa y que ataca a veces al entendimiento más sano; la segunda, una enfermedad que lo desorganiza. (KU, 5: 275). 
En la medida en que tanto las pasiones como las emociones ofrecen cierta resistencia a la actividad racional, Kant las considera "enfermedades"; sin embargo entiende que hay entre ellas una importante diferencia, que, en contra de lo que podría parecer, no se refiere al grado o la intensidad - como si la diferencia principal entre emociones y pasiones consistiera en que estas últimas fueran más intensas y las emociones menos, o viceversa:

Estar sometido a las emociones (Affekt, emotion) y a las pasiones (Leidenschaften, passions) es siempre una enfermedad del alma (Gemüth, mind), porque ambas excluyen el dominio de la razón. Ambas son también igualmente violentas por su grado; mas en lo tocante a su cualidad, son esencialmente diferentes, tanto en el método de prevenirlas como en el de curarlas que el médico de almas habría de aplicar. (Antr, 7: 251 (185)).

Como hemos visto, Kant vincula emoción y salud, señalando que la naturaleza se sirve de ellas para vitalizar el organismo. Desde esta perspectiva, podría sorprender que ahora se refiera a la emoción en términos de "enfermedad". Sin embargo, en este contexto, Kant está empleando el término "enfermedad" en sentido metafórico, refiriéndolo principalmente a la salud del alma, y no tanto a la salud del cuerpo. Desde este punto de vista, piensa, tanto la emoción como la pasión pueden considerarse enfermedades, pues ambas entorpecen el uso libre de la razón.

La consideración de las pasiones como "enfermedades" del alma tiene una larga historia (AQUINO, De Malo, q. 3, a.9). Tal vez lo novedoso resida en que, según Kant emociones y pasiones constituyen enfermedades muy diferentes. Pues aunque ambas excluyen el dominio de la razón, la emoción designa un sentimiento pasajero, que ataca por sorpresa pero se va igual de rápido que ha venido, sin que apenas mueva a la acción, mientras que la pasión pertenece a la facultad apetitiva, arraiga en ella de manera más persistente, y es motor de acciones (contrarias a la razón):

La emoción obra sobre la salud como un ataque apoplético: la pasión, como una tisis o consunción.- La emoción debe considerarse como una borrachera, que se duerme, si bien después se tiene dolor de cabeza: la pasión, como una enfermedad causada por la ingestión de un veneno o una degeneración, que necesita un médico de almas interior o exterior, el cual, sin embargo, las más de las veces no sabe prescribir ningún medio curativo radical, sino casi exclusivamente paliativos. (Antr. 7: 252 (185)). 
Desde el punto de vista psicológico, Kant hace notar una cierta incompatibilidad entre emoción y pasión - análogamente a como Hume distingue entre delicadeza de sentimiento y delicadeza de pasión - : “[...] donde hay mucha emoción existe comúnmente poca pasión” (Antr. 7: 252 (185)). Asimismo, mientras que muestra cierta indulgencia y aun simpatía por las emociones, condena sin paliativos las pasiones:

Las emociones son nobles y francas; las pasiones, por el contrario, astutas y solapadas... La emoción debe considerarse como una borrachera, que se duerme; la pasión, como una demencia, que incuba una representación que anida en el alma cada vez más profundamente. (Antr. 7: 252 (185)).

Kant asimila la pasión a una forma de inclinación persistente, que contamina la facultad de desear, pues, aunque no comporte una acción inmediata, siempre se opone al obrar según principios. Un ejemplo de ello es la pasión de la envidia (MS: 6: 459, (330-1)). En general,

Las pasiones, puesto que son compatibles con la más tranquila meditación, no teniendo que ser irreflexivas como la emoción, ni tampoco tormentosas y pasajeras, sino pudiendo arraigarse y coexistir incluso con el sutil argüir, causan el mayor quebranto a la libertad, y si la emoción es una borrachera, la pasión es una enfermedad que rehuisa toda medicina y, por ende, es mucho peor que todas aquellas conmociones pasajeras del alma, que, al menos, excitan el propósito de corregirse; en lugar de lo cual la pasión es un hechizo que excluye también la corrección. (Antr. 7: 255 (203-4)).

La ligadura de la razón que, según Kant, introduce la pasión se manifiesta en que el sujeto ya no razona partiendo de principios, sino que toma la pasión - transformada en inclinación - en una suerte de principio alternativo. Por ello, la oposición a los principios de la razón parece constitutiva de la misma noción Kantiana de pasión. Ello explicaría por qué, a juicio de Kant, no pueden atribuirse pasiones a los animales (Antr. 7: 255 (204)), sino sólo a los seres racionales: en la medida en que la oposición a la razón es constitutiva de la definición misma de pasión, los animales, que carecen de razón, no pueden tener tampoco pasiones, sino, a lo más, inclinaciones intensas (Antr. 7:269 (209)).

"De aqui" - concluye - "[...] que las pasiones sean, no meramente, como las emociones, sentimientos desgraciados, que están preñados de muchos males, sino también malas en sí, sin excepción, y el apetito de mejor 
índole, aunque se dirija a lo que corresponda (por la materia) a la virtud, por ejemplo, al beneficencia, es (por la forma), tan pronto se convierte en pasión, no perjudicial de un modo meramente pragmático, sino también recusable desde el punto de vista moral" (Antr. 7: 267 (205)).

De todo ello se desprende lo que anticipábamos más arriba: si bien cabría decir que el concepto kantiano de pasión - en la medida en que hace las veces de un principio - contiene un elemento cognitivo, dicho elemento cognitivo es intrínsecamente irracional, precisamente por oponerse a la razón.

\subsection{UN CONCEPTO ESTOICO DE PASIÓN}

Indudablemente, el concepto kantiano de pasión podría asimilarse al que, convencionalmente, se atribuye a los estoicos, quienes también designaban como pasiones los afectos desordenados, con la particularidad de que el desorden se encuentra instalado en la raíz misma del comportamiento, contaminando el obrar racional. De hecho, Kant califica a la pasión como demencia o cáncer de la razón práctica, en un sentido que, nuevamente, pone de relieve la función que, en el enfoque clásico corría a cargo de la cogitativa:

Las pasiones son cánceres de la razón pura práctica y, las más de las veces, incurables; porque el enfermo no quiere curarse y se sustrae al poder del único principio por obra del cual pudiera suceder esto. La razón va también en la esfera práctica sensible de lo universal a lo particular con arreglo al principio: no por complacer a una inclinación relegar todas las restantes a la sombra o a un rincón, sino cuidar de que aquélla pueda coexistir con la suma de todas las inclinaciones [...]. (Antr.7: 266 (204)).

Ahora bien: es precisamente este proceder de la razón, de lo universal a lo particular, con arreglo a principio, lo que queda impedido por la influencia perniciosa de la pasión. Vemos, así, que la pasión kantiana guarda muchas semejanzas con la caracterización que Aristóteles hace del vicio cuando afirma que "[...] el vicio corrompe el principio" (EN VI, 5, 1140b19). En efecto, escribe Kant:

Una propensión a un afecto (por ejemplo, la ira) no se hermana tanto con el vicio como la pasión. La pasión, en cambio, es el apetito sensible convertido en inclinación permanente (por ejemplo, el odio por contraposición a la ira). La tranquilidad con la que nos entregamos a ella 
nos deja reflexionar y permite al ánimo forjarse principios al respecto y, de este modo, cuando la inclinación conduce a lo contrario a la ley, permite incubarlos, arraigarlos profundamente e incorporar así (deliberadamente) el mal en la propia máxima: lo cual es entonces un mal cualificado, es decir, un verdadero vicio. (MS, 6:408 (265)).

\section{De ahí infiere Kant un peculiar deber de virtud: el deber de apatía:}

Por tanto, la virtud, por cuanto está fundada en la libertad interna, contiene también para los hombres un mandato positivo, a saber, el de someter todas sus facultades e inclinaciones a su poder (al de la razón), por tanto, el dominio de sí mismo, que se ańade a la prohibición de no dejarse dominar por sus sentimientos e inclinaciones (al deber de la apatía): porque si la razón no toma en sus manos las riendas del gobierno, aquéllos se adueñan del hombre. (MS, 6: 408 (266)).

Si lo que según Kant, motiva la valoración negativa de un estado emocional es el bloqueo de la capacidad de comparar el sentimiento en cuestión con la totalidad de los sentimientos (Antr. 7: 265 (203)), entonces el principio de la apatía es lo propio del sabio:

El principio de la apatía, a saber, que el sabio no debe nunca ser presa de la emoción, ni siquiera de la de la piedad hacia los males de su mejor amigo, es un principio moral sumamente justo y elevado de la escuela estoica; pues la emoción deja (más o menos) ciego. (Antr. 7: 253 (187)).

Alguien podría objetar que, si las emociones causan esta clase de ceguera, no tiene sentido que la naturaleza nos haya provisto de ellas. Pero Kant no está dispuesto a admitir que una provisión natural sea en vano: fue la misma sabiduría de la naturaleza la que ha implantado en nosotros la disposición para las emociones, como un modo de proporcionar ciertos resortes para el bien antes de que la razón haya llegado a su madurez, de tal manera que las emociones podrían considerarse "[...] como un sustituto interino de la razón" (Antr. 7: 253 (187).

Además, Kant reconoce a las emociones un papel en la vida moral, similar al que Tomás reconoce a las pasiones consiguientes al imperio de la razón, a saber: su capacidad de avivar el alma para el bien, siempre que la iniciativa parta de la razón (Antr. 7: 253-4 (188)). Pero, en todo caso, la razón 
ha de mantener las riendas. Por ello, piensa Kant, quien tenga esta cualidad de la apatía de modo natural tiene también más posibilidades de llegar a ser una persona feliz (Antr. 7: 254 (188)).

\section{Conclusión}

Llegados a este punto, y habida cuenta de las variaciones significativas sufridas por los términos "pasión" y "emoción", se comprende, por un lado, la resistencia contemporánea a emplear el término "pasión" en contextos psicológicos en los que se quiere aludir a la dimensión pasional del comportamiento, sin que tal cosa suponga necesariamente connotaciones morales negativas. Y se comprende, por otro, la resistencia a emplear el término emoción en clave cognitiva, por cuanto el uso no-cognitivo del término goza también de un largo recorrido: como afección orgánica que, suscitada por la imaginación o el juego de representaciones, constituye el punto álgido de un sentimiento y presenta la virtualidad de estimular la actividad psíquica del sujeto.

Al mismo tiempo, el análisis de los textos, y en especial la distinción entre sentimiento y emoción, plantea la conveniencia de reconsiderar el lugar de Kant en el debate filosófico sobre la emoción, hasta tiempos recientes polarizado por la controversia entre los partidarios de una "[...] feeling theory of emotions" (WHITTING, 2009) - para la que la emoción designa ante todo un estado mental diferente de los estados cognitivos, y los partidarios de una "teoría cognitiva de las emociones", para la que la emoción es principalmente una percepción o un juicio cualificado, expresable proposicionalmente (NUSSBAUM, 2001; SOLOMON, 1983; ROBERTS, 2003; KENNY, 1994). Mientras que la "feeling theory of emotions" da cuenta sobre todo el uso que se hace de la emoción en la psicología científica, la teoría cognitiva pretende dar cuenta del modo cualitativamente diferente con que se presentan las distintas emociones en la experiencia ordinaria.

De acuerdo con este modo convencional de presentar el debate, Kant aparentemente se situaría entre los feeling-theorists, pues, atendiendo al uso estricto del término "emoción", ésta consiste en una afección orgánica completamente vacía de todo contenido cognitivo. Sin embargo, si contemplamos la emoción en el contexto más amplio del sentimiento, del que forma parte, o la identificamos directamente con lo que Kant denomina "sentimiento", entonces su postura refleja una visión mucho más rica de la experiencia emocional, pues el sentimiento se presenta al sujeto con 
pretensiones informativas sobre el objeto, incluso aunque tales pretensiones no puedan ser contrastadas objetivamente y catalogadas como "conocimiento", en el sentido estricto del término. Desde esta perspectiva, por tanto, Kant aparecería como un autor intermedio entre la feeling theory of emotions y las teorías cognitivas, cercano a lo que recientemente se ha designado como "[...] new-feeling theory of emotions" (KRIEGEL, 2014).

GONZÁLEZ. Ana Marta. Emotion, Feeling, and Passion in Kant. Trans/Form/Ação, Marilia, v. 38, n. 3, p. 75-98, Set./Dez., 2015.

\begin{abstract}
In this article I analyze Kant's distinction between feeling (Gefühl) and emotion (Affekt), on the one hand, and emotion and passion (Leidenschaft), on the other. The objective is to show: 1) that by the term "emotion" he understands organic affection, deprived of cognitive content, although preceded and followed by representations; 2) that emotion so understood constitutes for Kant an integral part of "feeling" (Gefühl), by which Kant designates the subjective dimension of experience, in a broad sense, which is not limited to empirical affection; 3) that his negative approach to passion justifies the sharp distinction between emotion and passion introduced in scientific studies of emotion.
\end{abstract}

KEYWORDS: Charm. Aesthetic judgment. Health. Art and play. Desire.

\title{
REFERENCIAS
}

AQUINO, Tomás de. Suma de Teologia, I, Madrid: BAC, 1998; Suma de Teología, II. Madrid: BAC, 1989.

De Veritate. In: . Opera Omnia: iussu Leonis XIII P. M. Edita. Roma: Editori di San Tommaso, 1975. t. 22, v.1-3.

De Malo. In: Opera Omnia: iussu Leonis XIII P. M. Edita. Roma: Commisio Leonina; Paris: J.Vrin, 1982. t. 23.

ARISTÓTELES. Ética a Nicómaco. Traducción de Julián Marías y María Araújo. Madrid: Centro de Estudios Politicos y Constitucionales, 1987.

BORGES, M. What can Kant teach us about emotions? The Journal of Philosophy, v. 101, n. 3, p. 140-158, mar. 2004.

DIXON, T. From passions to emotions: the creation of a secular psychological category. Cambridge: Cambridge University Press, 2003.

ENGSTLER, A.; SCHNEPF, R. (Hrsg.). Affekte und Ethik. Spinozas Lehre in Kontext. Hildesheim: Georg Olms, 2002.

GONZÁLEZ, A. M. Naturaleza y elementos de una concepción cognitivo-práctica de las emociones. Pensamiento, v. 67, n. 253, 2011. 
GRIFFITHS, P. E. Current emotion research in philosophy. Emotion Review, v. 5, n. 2, p. 215-222, 2013.

HERMAN, B. Moral literacy. Cambridge: Harvard University Press, 2007.

KANT, I. Antropología. Traducción José Gaos. Madrid: Alianza, 1991. Original: Anthropologie in pragmatischer Hinsicht (1798). Kant's Werke. Berlin: Druck und Verlag von Georg Reimer, 1917. Bd. 7.

. Crítica del Juicio. Edición de Juan José García Norro y Rogelio Rovira, traducción de M. García Morente. Madrid: Tecnos, 2007. Original: Kritik der praktischen Vernunft (1788). Kant's Werke. Berlin: Druck und Verlag von Georg Reimer, 1913. Bd. 5.

Ideas para una historia universal en clave cosmopolita y otros escritos sobre Filosofía de la Historia. Edición de Roberto Rodríguez Aramayo; traducción Concha Roldán y Roberto Rodríguez Aramayo. Madrid: Tecnos, 1994. Original: Idee zu einer allgemeinen Geschichte in weltbürgelicher Absicht (1784). Kant's Werke. Berlin: Walter de Gruyter \& Co., 1923. Bd. 8.

. Metafísica de las Costumbres. Trad. Adela Cortina y Jesús Conill. Madrid: Tecnos, 1989. Original: Die Metaphysik der Sitten (1797). Kant's Werke. Berlin: Druck und Verlag von Georg Reimer, 1914. Bd. 6.

- Religión dentro de los limites de la mera razón. Trad. Felipe Martínez Marzoa. Madrid: Alianza, 2001. Original: Die Religion innerhalb der Grenzen der blossen Vernunft (1793). Kant's Werke. Berlin: Druck und Verlag von Georg Reimer, 1914. Bd. 6.

KENNY, A. Action, emotion, and will. Bristol: Thoemmes Press, 1994.

KRIEGEL, U. Towards a new feeling-theory of emotions. European Journal of Philosophy, v. 22, n. 3, p. 420-442, 2014. DOI: 10.1111/j.1468-0378.2011.00493.x.

MARSHALL, E. Spinoza's cognitive affects and their feel. British Journal for the History of Philosophy, v. 16, n.1, p. 1-23, 2008.

NUSSBAUM, M. C. Upheavals of thought. Cambridge: Cambridge University Press, 2001.

ROBERTS, R. C. Emotions: an essay in aid of moral psychology. Cambridge: Cambridge University Press, 2003.

RORTY, A. O. From passions to emotions and sentiments. Philosophy, v. 57, p. 159-172, 1982.

ROSENKRANZ, M. From passion to emotion: the creation of a secular psychological category (review). Journal of the History of Philosophy, v. 43, n. 2, p. 214-215, abr. 2005.

SANCHEZ MADRID, N. Las pasiones y sus destinos: el examen de las emociones en las Lecciones de Antropología de Kant. Ideas y Valores, v. 62, n. 1, p. 109-132, 2013.

SEGAL, G. Beyond subjectivity: Spinoza's cognitivism of the emotions. British Journal for the History of Philosophy, v. 8, n.1, p. 1-19, 2000. 
SOLOMON, R. The Passions: the myth and nature of human emotions. Notre Dame, Indiana: University of Notre Dame Press, 1983.

WHITING, D. The feeling-theory of emotions and the object-directed emotions. European Journal of Philosophy, v. 19, n. 2, p. 281-303, 2009.

Recebido / Received: 06/02/2015

Aprovado / Approved: 03/04/2015 
GONZÁLEZ, A. M. 